Slavica

bruxellensia

\section{Slavica bruxellensia}

Revue polyphonique de littérature, culture et histoire

slaves

$2 \mid 2009$

Femme(s)

\title{
Savourez Ocalone w tlumaczeniu de Stanisław Barańczak
}

Dorota Walczak

(2) OpenEdition

Journals

Édition électronique

URL : http://journals.openedition.org/slavica/165

DOI : $10.4000 /$ slavica. 165

ISSN : 2034-6395

Éditeur

Université libre de Bruxelles - ULB

Édition imprimée

Pagination : 66-67

ISSN : 2037-7654

Référence électronique

Dorota Walczak, «Savourez Ocalone w tłumaczeniu de Stanisław Barańczak», Slavica bruxellensia [En ligne], 2 | 2009, mis en ligne le 15 février 2009, consulté le 02 mai 2019. URL : http:// journals.openedition.org/slavica/165; DOI : 10.4000/slavica.165

Ce document a été généré automatiquement le 2 mai 2019.

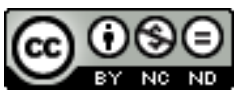

Les contenus de Slavica bruxellensia sont mis à disposition selon les termes de la Licence Creative Commons Attribution - Pas d'Utilisation Commerciale - Pas de Modification 3.0 France. 


\title{
Savourez Ocalone w tłumaczeniu de Stanisław Barańczak
}

\author{
Dorota Walczak
}

1 Que je me réjouis de voir la nouvelle édition du mois de janvier, la quatrième si je compte bien (les précédentes datent de 1992, 1994 et 2004), une édition encore plus belle et plus soignée d'un livre qui mérite une place bien visible sur les étagères des bibliothèques professorales, estudiantines, « poétiques ». Et éclectiques aussi...

2 Parce qu'il s'agit d'un des ouvrages les plus importants du richissime curriculum vitae de Stanisław Barańczak (né en 1946 à Poznań), autrement dit d'un auteur et d'une œuvre, insistons, exceptionnels. Faisons-nous plaisir et citons le titre complet qui fait déjà office de carte de visite : Ocalone $w$ thumaczeniu. Szkice o warsztacie poezji z dołĄczeniem małej antologii przekładów (Sauvé dans la traduction.

Esquisses sur l'atelier de poésie, accompagnées d'une petite anthologie de la traduction)'. C'est surtout le titre de la première partie qui est à couper le souffle et qui annonce le tempérament littéraire auquel nous allons avoir affaire.

3 Le voici :

4 Même si ce titre nous défie en jouant avec le sens des termes «tłumaczyć » (traduire, expliquer), «wytłumaczyć siĘ » (s'expliquer, se justifier), nous pourrions essayer de le traduire comme ceci : 
5 Ainsi, le lecteur qui ne connaît pas du tout Barańczak remarquera directement les qualités de ce livre, imposant en nombre de pages : son caractère explicatif et narratif, voire conteur, un sens de l'humour omniprésent, la créativité, la taquinerie mais aussi l'assiduité de l'auteur. Les parties suivantes, les chapitres et les sous-chapitres portent des noms colorés comme des signaux bariolés, comme des panneaux indicateurs sur la route souvent grise (car laborieuse) du traducteur.

6 Or, Barańczak, lui-même poète, partage avec ferveur et ingéniosité son expérience en matière de traduction, et ce sous une approche pédagogique qui rend cette matière délicate accessible aux débutants, dévoilant en même temps ses secrets de cuisine littéraire aux plus instruits. Bien qu'il s'agisse ici de traduction vers la langue polonaise, le savoir présenté dans ce livre est en grande partie universel, puisque Barańczak se met dans la peau d'un intelligent détective enthousiaste qui traque les faiblesses et les fautes commises par les potentiels traducteurs que sont les lecteurs et les lecteurs amateurs qui, hélas, ne sont pas suffisamment attentifs aux valeurs d'un texte poétique.

Barańczak, auteur d'innombrables textes critiques consacrés à la littérature, auteur d'une douzaine de volumes poétiques, de six anthologies de traduction et de dizaines de traductions de poètes différents, auteur de la nouvelle traduction de vingt-quatre pièces de William Shakespeare et j'en passe..., en sait quelque chose de la lecture soignée de textes. Et en plus, il veut partager ce savoir! Dans Ocalone w thumaczeniu, Barańczak nous invite, entre autres, à se pencher sur les problèmes particuliers de la traduction pour enfants, de la poésie particulière de Bolesław Leśmian ou de Miron Białoszewski, qu'il traduit vers l'anglais. Il nous relate aussi l'expérience du duo particulier qu'il forme avec l'américaine Clare Cavanagh. Là, c'est un poème de Wisława Szymborska qui donne du fil à retordre au traducteur.

8 L'immense et époustouflant travail que constitue Ocalone $w$ thumaczeniu nous montre combien il est basique et indispensable de bien lire, tenter de comprendre et aimer l'univers de l'auteur que l'on aborde. Combien il est important de garder l'esprit critique, sa joie de vivre de lecteur et la joie de faire vivre le texte. Aussi faut-il examiner l'intertextualité de l'œuvre qu'on traduit, la biographie de l'auteur et ses propres ressources. Et apprendre à lire. Et lire pour d'apprendre.

9 Il nous présente un choix de quarante poèmes, dans leur version originale et en traduction, et il décrit la démarche qu'il adopte face à des poèmes qui datent du XIV ${ }^{\mathrm{e}}$ jusqu'au $\mathrm{XX}^{\mathrm{e}}$ siècle. Nous y trouverons exposées les problématiques liées aux langues espagnole, lituanienne, allemande et russe mais surtout anglaise. Il touche des auteurs tels que Rainer Maria Rilke, Anna Akhmatova, Osip E. Mandel'štam, Marina Cvetaeva, Josif Brodskij, Geoffrey Chaucer, John Donne, Robert Burns, John Keats, Emily Dickinson, E. E. Cummings, ainsi que, cerise sur le gâteau, John Lennon et Paul McCartney. Les poèmes de ceux-ci sont présentés comme des devinettes (les solutions sont proposées), ce qui n'enlève rien à l'effet de surprise tellement chéri par l'auteur de cet ouvrage. Ajoutons que Ocalone $w$ thumaczeniu peut être lu comme un polar ou comme une anthologie poétique, comme un traité philosophique, un manuel de traduction ou une satire. Ce livre instructif constitue aussi une création artistique en soi. Bien que certains critiques discutent l'audace des traductions barańczakiennes, il reste indéniable que Ocalone w thumaczeniu est le livre passionnant d'un auteur passionné. 
INDEX

Index géographique : Pologne

Mots-clés : littérature polonaise

Index chronologique : époque contemporaine, XXe siècle

oeuvretraite Barańczak St.: Ocalone w tłumaczeniu

\section{AUTEURS}

\section{DOROTA WALCZAK}

Responsable de la Chaire de Polonais, section de Langues et Littératures modernes, option Slaves, de l'Université Libre de Bruxelles (Belgique) ; rédactrice en chef de Slavica Bruxellensia 